\title{
'Revelando' Histórias: os usos do audiovisual na pesquisa com narradores da fronteira entre Argentina, Brasil e Uruguai
}

Luciana Hartmann Na zona de fronteira entre Brasil, Argentina e Uruguai, a população possui fortes

UFRJ laços de identificação entre si, fortalecidos pela intensa convivência estabelecida ao longo de sua história. Esta convivência persiste, atualmente, nos âmbitos mais diversos, como nos laços de parentesco, na educação, no lazer, no comércio (e em uma de suas formas locais características, o contrabando), no trabalho etc. Neste contexto, as narrativas orais, que transitam 'sem-fronteiras' - nem mesmo de idioma - funcionam como um importante instrumento na afirmação e na transmissão destes vínculos e deste imaginário comum (Hartmann 2004).

Em minha pesquisa de campo procurei acompanhar, através da 'rede' existente entre os contadores de histórias dos três países fronteiriços, os caminhos percorridos pelas narrativas orais. Meu campo foi, assim, itinerante: viajei através das fronteiras à procura das histórias e dos sujeitos que as contam. A cada encontro com um novo contador, com uma nova narrativa, com uma nova paisagem, registrei imagens e sons com equipamento de vídeo, áudio e foto. Esta pesquisa, que durou cerca de oito meses, revelou não apenas um conjunto de histórias e performances narrativas características, como também uma maneira de ver e de se ver 'da fronteira', na qual identidades e alteridades se alternam conforme o contexto. É este ambiente de diálogo, de troca de conhecimentos e sobretudo de reflexão, potencializado na pesquisa antropológica realizada com recursos audiovisuais, que será abordado neste artigo.

Para melhor exposição destas questões, o artigo divide-se em três partes. $\mathrm{Na}$ primeira procuro evidenciar alguns referenciais teóricos que estimularam a utilização do audiovisual em minha pesquisa; na segunda, forneço um pequeno histórico do 
das diferentes perspectivas de abordagem da "antropologia visual", situando minha pesquisa neste contexto; finalmente, apresento dados empíricos a partir dos quais busco refletir sobre as múltiplas implicações que os recursos audiovisuais tiveram na pesquisa com os narradores da fronteira.

\section{A IMAGEM COMO VEÍCULO PARA COMUNICAR}

Assumindo a perspectiva de que a utilização do audiovisual apresenta alternativas para a tradução e interpretação de expressões culturais, pois envolve os antropólogos não apenas no registro e análise dos fenômenos pesquisados, mas na criação de novas obras expressivas, vejamos, de maneira sucinta, como o debate sobre o papel do antropólogo como intérprete e como autor (Geertz 1989a e 1989b) se refletiu no campo específico da antropologia (áudio) visual ${ }^{1}$.

O impasse vivido historicamente pela antropologia, entre relativismo-universalismo, tem como pano de fundo uma questão epistemológica de primeira ordem: afinal, o conhecimento e o significado das formas culturais produzidas pelas mais diferentes sociedades são comunicáveis e traduzíveis ou não? Na tentativa de responder à questão encontramos, de um lado, tendências universalistas que buscam uma provável unidade na diversidade de manifestações humanas e, de outro, perspectivas relativistas, que privilegiam as diferenças, especialmente se puderem ser descritas em seus próprios termos.

Na oscilação de teorias, alternadas nos diferentes períodos e escolas que deram forma ao fazer antropológico ao longo do século $\mathrm{XX}$, pode-se perceber uma inversão gradual entre as pretensões objetivistas-universalistas e as subjetivistas-relativistas, passando os antropólogos, a partir de uma ênfase cada vez maior nesta última, a colocarem a si mesmos e à disciplina apenas como mais um nó nessa teia (aproveitando a metáfora geertziana) por onde passam múltiplas possibilidades de interpretação e de atribuição de significado às expressões culturais.

Ainda que num primeiro momento da disciplina a preocupação fosse estabelecer a antropologia como ciência e num momento seguinte a própria sobrevivência do seu 'objeto' (o exótico, o primitivo) passasse a ser questionada, a crise instaurada pelo relativismo, levado ao extremo pelos 'pós-modernos', veio realmente para abalar a disciplina e colocá-la frente a frente com a sua mais cara conquista, justamente a questão da sua pertinência em dar respostas sobre o que, especificamente, caracteriza nossa humanidade / nos torna humanos.

Mas, afinal, o conhecimento e o significado das formas culturais produzidas pelas mais diferentes sociedades são comunicáveis e traduzíveis ou não?

Embora as diversas correntes antropológicas procurem estabelecer critérios e propostas de abordagem para 
realizar esta tradução, ou "interpretação das culturas", foi somente depois da crise deflagrada pelo relativismo (Soares 1994) que esta questão passou a participar da pauta diária de debates da disciplina. Parte do 'desmascaramento' proposto pelos antropólogos relativistas atingiu o meio até então privilegiado de produção do conhecimento antropológico, o texto, que passou a ser escrutinado, investigado, até ser despojado de sua aura de verdade para ser considerado, ele próprio, um produto de sujeitos e teorias produzidos por uma cultura, ou seja, passou a ser considerado relativo ao que é concebido como conhecimento antropológico nesta cultura. Algumas das principais certezas que garantiam aquilo que Clifford (1998) chama de "autoridade etnográfica" ${ }^{2}$, vigente durante tanto tempo, foram sacudidas por questionamentos como: se o meio privilegiado de transmissão do saber antropológico é a escrita, a que regras (culturais) esta está submetida? Quem escreve, em que momento, e para quem? O que os "nativos" pensam a respeito de sua própria cultura? Como dar-Ihes participação efetiva neste momento de produção de conhecimento tão culturalmente (para não dizer ocidentalmente) determinado? O que este 'novo' conhecimento produzido pelos antropólogos realmente pode acrescentar à compreensão da cultura estudada?

Torna-se necessário, então, que a interpretação dada pelo antropólogo à sociedade pesquisada seja ela também relativizada. E, mais importante, a interpretação dos 'nativos' passa a ser privilegiada, alçando estes da condição de objeto para o status de sujeito antropológico, com os antropólogos assumindo seu papel como criadores de uma obra, muitas vezes compartilhada, em suas várias etapas, com estes sujeitos da pesquisa. É justamente neste ponto que quero tratar da introdução dos recursos audiovisuais na antropologia.

\section{OS USOS DO AUDIOVISUAL EM ANTROPOLOGIA}

De acordo com Piault (2000), é engano pensar que tenha havido uma antropologia antes e outra depois da imagem. Ao contrário, ele demonstra que o surgimento da disciplina esteve colado à revolução tecnológica que permitiu a apreensão de imagens em movimento ${ }^{3}$, e como ambos - numa relação de interdependência - estavam voltados naquele momento a explorar a alteridade do mundo. Segundo o autor (2000: 8), tanto o cinema quanto a antropologia desenvolveram, desde o final do século XIX, uma "obsessão inventarial", onde o acúmulo de curiosidades e exotismos do planeta era utilizado em comparações e medidas que tomavam como parâmetro a normalidade ocidental. Grande parte da crítica construída por Piault se dirige justamente à forma com que o registro através da imagem e do som era utilizado na época pois, colocado a serviço das empresas colonialistas, realizava o desejo mascarado de dominação que o homem ocidental projetava no outro. Para ele, absorvia-se a distância material do outro reduzindo-o a imagem ${ }^{4}$. 
$\mathrm{Na}$ abordagem de Piault, da qual compartilho, a antropologia audiovisual deve ser considerada não somente como um espaço de produção com e pela imagem e som mas, acima de tudo, como o lugar onde os processos desta produção serão problematizados, inserindo-a no seio de uma reflexão epistemológica sobre o próprio desenvolvimento da disciplina.

Se a utilização de imagens nas ciências sociais não é recente ${ }^{5}$, em muitos casos era-lhe (e o é até hoje em muitos casos) atribuída uma função meramente ilustrativa, como um adereço ou um índice afirmativo do texto escrito - não devemos esquecer que a fotografia, por ser um meio de construção de imagens resultante de pesquisas científicas, era tida, até meados do século XX, como um "espelho do real" (Dubois apud Santos 1998: 33). Assim, esta forma de emprego das imagens relacionava-se também a um desejo de reafirmação da autoridade do antropólogo, funcionando como uma prova de "ter estado ali" (Geertz 1989b).

Uma outra perspectiva, no entanto, começa a ganhar espaço a partir da crise do texto: a fotografia, e mais recentemente o vídeo, passam a ser considerados também como um "recorte da realidade", resultante do olhar de um sujeito que foi preparado, educado por uma cultura. "Imagens, tais como textos, são artefatos culturais", afirma Novaes (1998:116).

A convergência entre a crise relativista e os implementos tecnológicos na área de captação audiovisual possibilitaram que as imagens, estáticas ou em movimento, deixassem de ocupar papéis secundários na cena antropológica e passassem a protagonizar um grande número de pesquisas nesta área. Para melhor demonstrar como se dão as diferente abordagens no que passou a se chamar "antropologia visual", classifico-as da seguinte maneira, tomando como referência trabalhos recentes de antropólogos, sobretudo brasileiros:

1. Aquelas que tomam a imagem, especialmente a fotografia, como um produto histórico-cultural passível de tornar-se objeto de análise. Nos trabalhos de Bianco (1998), Kossoy (1998), Leite (1998), Oliveira Jr. (1998) e Rial (1999), entre tantos outros, fotografias, imagens publicitárias, retratos do passado e do presente são examinados, à luz de argumentos antropológicos, como formas expressivas representativas de uma época e de uma cultura. Nestas pesquisas, propostas estéticas e posturas éticas são depreendidas dos produtos visuais, sempre cotejadas com seu contexto sócio-cultural de produção.

2. Aquelas que utilizam os recursos audiovisuais como forma de estabelecer um diálogo intercultural (Gallois e Carelli 1995; Peixoto 1995; Valadão 1999). Neste grupo incluo os pesquisadores que realizam experiências com a utilização da linguagem audiovisual pelos próprios sujeitos da pesquisa, vislumbrando com isso a criação de condições para que tanto a linguagem quanto o conteúdo das informações/conhecimentos transmitidos representem mais diretamente os sujeitos em questão. Considero aqui também aqueles antropólogos que realizam seus trabalhos em 'co-produção' com o grupo, numa proposta de atuação menos autoritária, onde o produto final é parte fundamental na demonstração deste trabalho conjunto. 
3. Aquelas que investigam e analisam as produções e os experimentos com a linguagem audiovisual na antropologia (Bittencourt 1998; Darbon 1998; Eckert e Rocha 2000; Fonseca 1995; Ginsburg 1999; Guran 1998; Lourdou 2000; Novaes, 1998; Rocha 1995 e 1999; Sel 1995). Estes autores abordam epistemologicamente a presença do audiovisual nos trabalhos antropológicos, considerando o emprego dos métodos e técnicas relativos a essa linguagem de acordo com suas implicações na construção, transmissão e troca de conhecimentos. Esta perspectiva também contempla a proposta de construção de uma "antropologia da visualidade humana", assim denominada por Samain (1995), orientada para o estudo das estruturas e códigos dos mecanismos neurofisiológicos e sensoriais que servem de base ao pensamento humano.

4. Aquelas para quem os recursos audiovisuais funcionam como uma "moeda de troca", como uma forma de dar um retorno à comunidade estudada (Pólvora 1995). Essa é uma estratégia bastante utilizada nas pesquisas antropológicas, sejam elas voltadas ou não ao estudo da linguagem audiovisual pois, ainda na atualidade, em muitos grupos brasileiros, tanto do meio urbano quanto rural, as fotografias, e numa escala maior, vídeos, continuam sendo objetos raros e caros. Essa forma de 'troca' não apenas é bem-vinda para muitos informantes como também esses produtos acabam representando, em muitos casos, novas e importantes fontes de informação sobre como os sujeitos vêem a si mesmos e como vêem o papel do antropólogo no contexto da pesquisa.

5. Aquelas que utilizam as imagens como alternativa à narrativa etnográfica ou como uma nova forma de produzir e transmitir o conhecimento etnográfico (France 1998; Godolphim 1995; Maresca 1998). O sentido que norteia esta abordagem é o de que a escrita, tradicional linguagem utilizada pela narrativa antropológica, poderia ceder lugar a outras formas de linguagem, pautadas no uso combinado de imagens e sons. Através do audiovisual, a antropologia encontraria uma linguagem mais completa para se expressar.

6. Finalmente, aquelas que vêem o registro audiovisual como recurso imprescindível na apreensão de (determinadas) expressões culturais, sendo que o próprio registro torna-se objeto de análise e serve como material bruto para produções posteriores - vídeos, mostra de fotos, filmes etc. (France 2000; Guéronnet 2000; Magni 1995). Essa perspectiva notabilizou-se, a princípio, na representação (áudio)visual de festas, rituais, danças e outras manifestações expressivas, notoriamente difíceis de apreender em sua totalidade através da escrita. Atualmente esta corrente envolve todos aqueles antropólogos que se identificam também como realizadores, adotando os recursos de imagem/som tanto como um instrumento para suas pesquisas quanto como um meio de expressão e comunicação destas. 
É importante considerar, no entanto, que estas perspectivas não são excludentes, sendo que muitas delas, inclusive, combinam-se. Minha pesquisa segue especialmente a última tendência apontada acima, ainda que, com exceção das abordagens 1 e 2, utilize também algo das outras perspectivas e estratégias ao longo do trabalho. Vejamos a seguir como, no curso de minha pesquisa, o uso dos recursos audiovisuais foi, em vários sentidos, determinante.

\section{O AUDIOVISUAL NA PESOUISA COM NARRADORES DA FRONTEIRA: DIALOGISMO E INTERPRETAÇÕES DA CULTURA ATRAVÉS DA IMAGEM}

Ao iniciar a pesquisa de campo, circulando sobretudo nas áreas rurais da fronteira - caracterizadas pela existência de grandes estâncias de criação extensiva de gado - fiquei atenta para as especificidades das relações que eram estabelecidas com os sujeitos a partir do uso dos equipamentos de registro. Uma das questões que logo despontou foi que meu papel em meio ao grupo se definia, justamente, a partir do manejo destes equipamentos. Vendo-me um dia sem a filmadora nem a máquina fotográfica em punho, um peão da estância onde eu estava hospedada me perguntou: "A senhora não vai trabalhar hoje, Dona Luciana?"

Assim como minha presença ali se justificava, para eles, de certa forma, pelo meu interesse e dedicação à realização de registros, o produto destes registros também foi significativo para o fortalecimento dos meus laços com a comunidade, bem como para a compreensão dos códigos e regras que organizam a cultura local. No caso das fotografias, estas serviam como uma forma de retribuição aos narradores e seus familiares, além de representarem um recurso de aproximação e legitimação da pesquisa frente aos seus sujeitos. Foi o que ocorreu quando levei as fotos que havia realizado em minha primeira ida a campo e as mostrei, num outro momento, a contadores residentes em outras localidades. As imagens apresentadas acabaram expondo novas facetas da 'rede de contadores', pois houve o reconhecimento de alguns participantes das fotos, revelando laços de amizade, trabalho e/ou parentesco entre eles, denotando o alcance da "comunidade narrativa" (Lima 1985) estudada.

Minha perspectiva envolve, desde então, uma combinação de diferentes formas e funções relativas ao uso da linguagem audiovisual na antropologia. Durante meu processo de pesquisa os recursos audiovisuais são utilizados, em primeiro lugar, como meio de registro de eventos complexos, as performances narrativas, que apenas a linguagem verbal não permite apreender. ${ }^{6}$ "Ao que é impossível descrever, torna-se indiscutível a prioridade da imagem, por sua capacidade de reproduzir e sugerir, por meios expressivos e artísticos, sentimentos, crenças e valores" (Leite 1998:44). 
Em segundo lugar, uma seleção representativa dos registros fotográficos - e, quando há oportunidade, dos registros videográficos também - é mostrada aos participantes da pesquisa, que fazem a exegese das imagens. Comentários e interpretações a respeito destas imagens/sons contribuem para a compreensão das peculiaridades do contexto: atitudes, posturas corporais, vestimentas, uso de objetos, que identificam os habitantes de cada microrregião e que são utilizados como importante fonte de informações sobre a relação que os sujeitos estabelecem entre a visão do outro e a visão de si mesmos, especialmente em se considerando que a região pesquisada envolve a zona fronteiriça de três países.

Em terceiro lugar, estes registros permitem que a análise das expressões vocais e corporais, especialmente, e dos eventos narrativos como um todo, incluindo o local, a audiência, os ruídos, as luzes, as cores etc. seja realizada detalhadamente, através da possibilidade de manipulação ilimitada deste material, já fora da situação de campo.

Em quarto lugar, as melhores fotos de cada contador e de suas famílias são distribuídas a estes, como forma de retribuição por sua colaboração. Finalmente, uma seleção destes registros foi utilizada na construção do material escrito relativo à pesquisa (tese de doutorado), bem como na produção do vídeo etnográfico Esses têm história - causos e cuentos de fronteira.

A seguir procuro aprofundar a discussão sobre os aportes que os recursos audiovisuais trazem à pesquisa antropológica, especialmente no tocante às peculiaridades das relações estabelecidas com o uso destes no encontro etnográfico e às qualidades interpretativas estimuladas pelo contato dos sujeitos (antropólogo x informantes) com os suportes imagéticos. Esta discussão será efetuada tendo como referência a presença destes elementos em minha própria pesquisa.

Como venho colocando, meu trabalho entre os contadores de causos/cuentos da fronteira vem, desde o seu início, sendo pautado pelo uso do audiovisual. Imagens e sons, quando reproduzidos, parecem emanar uma certa magia que atinge a todos, estejam mais ou menos familiarizados com estes veículos. Magia porque permite ver/ouvir uma parte de si e de sua cultura representada, impregnada num objeto, foto ou vídeo, transformada.

Em minha abordagem privilegio como os recursos audiovisuais interferem, estabelecem e estimulam as relações em campo, em detrimento de por que o fazem. Esta segunda forma de abordagem exigiria uma incursão no campo dos estudos sobre a cognição humana e sua relação com o uso das 'tecnologias' de comunicação que fogem ao propósito deste trabalho ${ }^{7}$. Assim, a partir da descrição de episódios-chave, representativos da importância do uso destes recursos no desenvolvimento de minha pesquisa, pretendo analisar suas implicações para o trabalho antropológico num sentido mais amplo.

No primeiro dia de minha pesquisa de campo compareci a um grande almoço (não por acaso um churrasco) que reunia moradores das cidades de Rivera/UY e Santana do Livramento/BR. Enquanto procurava me familiarizar 
com o evento e com os participantes, conheci um dos assadores, um senhor já idoso, todo pilchado (isto é, trajado com a vestimenta tradicional do gaúcho/gaucho: botas, bombachas, chapéu e lenço no pescoço; no caso da mulher, vestida de prenda/china), muito simpático. Aos poucos fui me introduzindo na roda de conversa que se formava ao redor da churrasqueira e explicando o que eu fazia ali. Aquele senhor, então, ao saber que eu queria 'ouvir histórias', logo se manifestou dizendo que conhecia muitas. Pedi-lhe permissão para buscar a filmadora, ao que ele respondeu enfaticamente: "Pero yo sólo hablo se hay una grabadora!"

Ainda que desde o início nossa relação tenha sido pautada pela presença do equipamento de registro, não nego que sua resposta me surpreendeu pois, ao invés de uma reação constrangida ou desconfiada, o contador inseriu o próprio equipamento como condição necessária à sua atuação. Assim, além de funcionar como um estímulo à performance, a filmadora, no caso, passou a fazer parte do evento, já que o narrador utilizou-a como mote, cômico inclusive, para iniciar suas narrativas.

Esta inteligência na apropriação dos equipamentos por parte dos contadores foi uma constante durante toda a pesquisa. Isto não significa, entretanto, que houvesse, por parte de todos, um domínio ou compreensão absolutos da tecnologia em questão. Havia, isto sim, a demonstração de que eles, como hábeis narradores, possuíam uma grande capacidade de lidar com os estímulos trazidos pelo seu público - no caso eu, meu interesse e meus aparatos eletrônicos.

Assim como o ato de filmar foi apropriado por Don López (mencionado acima), em outras ocasiões também foi o motor para a realização de performances. Um jovem arrendatário de uma estância em Barra do Quaraí/BR, por exemplo, ao me ver com a filmadora, contou que um há algum tempo um amigo da família quis filmar um dos peões. Assim que percebeu, o peão ficou imóvel, como uma estátua, esperando pela filmagem. 0 homem, no entanto, queria registrar um comportamento mais 'natural' e pediu que ele se movimentasse um pouco. $O$ peão então começou a se movimentar muito lentamente, com pernas e braços afastados, mas sem sair do lugar. Segundo o jovem narrador, "parecia um astronauta!"

Esta narrativa, além de contada através de uma competente performance (o rapaz inclusive se levantou para representar o gestual do peão), revela as diferentes expectativas criadas em torno desta forma de registro. Enquanto para o peão aquela era uma situação anti-natural, daí sua postura incerta e desconfortável, para o homem que filmava o registro deveria dar conta da realidade, mesmo que para isso tivesse que forjá-la (já que, afinal de contas, a postura 'natural' do peão não foi compatível com a sua proposta).

Embora enquanto filmasse eu nunca tenha enfrentado uma situação semelhante, no momento de fotografar era praxe os contadores assumirem uma postura sóbria, de extrema seriedade, o que muitas vezes contrastava com os momentos animados que havíamos passado durante a conversa (foto 1 - Don Zaracho - Argentina). Minha 
reação frente a estas atitudes, no entanto, foi sempre de respeito, procurando reconhecer na expressão de cada contador a projeção que estes sujeitos fazem de si, de como desejavam ver-se e mostrar-se.

Don Zaracho - Argentina

Outra situação, também bastante representativa, aporta informações sobre os significados atribuídos pela sociedade pesquisada à imagem: eu já havia conversado algumas vezes com Dona Nair, de Cerro Pelado/UY, e sempre registrava nossas conversas em fita cassete. Após conhecê-la melhor e ao seu repertório de histórias, pedi para filmá-la. Ela aceitou prontamente e naquela ocasião, frente à filmadora,

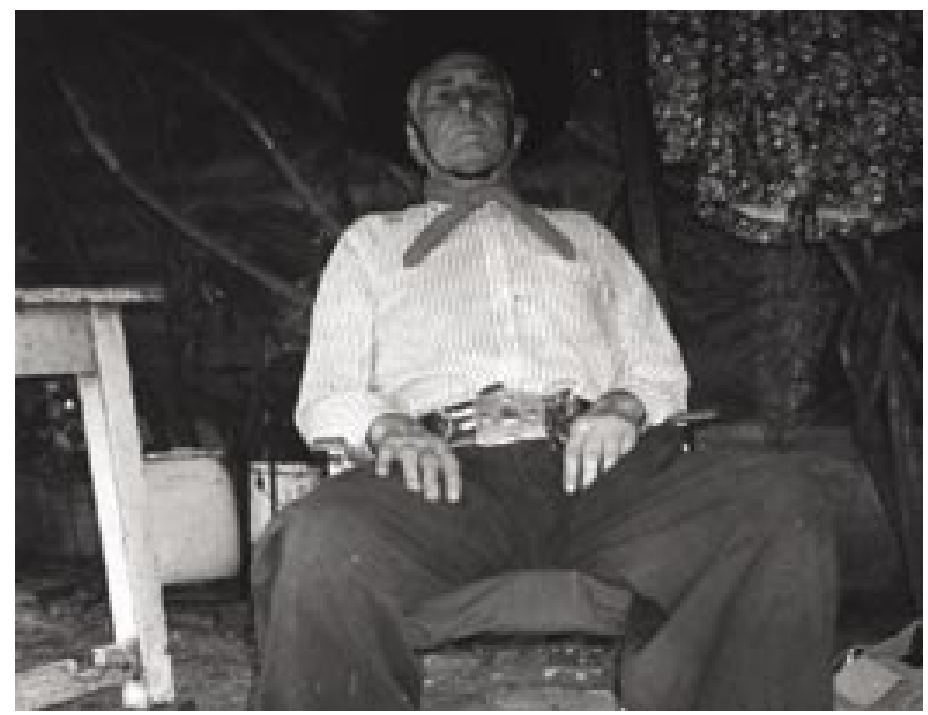
sua performance não ocorreu de maneira diferente. Durante nossas conversas era comum que seus netos circulassem pelo ambiente, curiosos pela minha presença e pelo uso do equipamento, mas não se demoravam ali, nem demonstravam qualquer interesse nas histórias da avó. Após a filmagem, percebendo a existência de uma televisão na sala, ofereci à Dona Nair para exibir-lhe as imagens que acabávamos de realizar. Ela ficou bastante entusiasmada com a idéia, mas pediu que eu não começasse antes que ela chamasse a nora e a filha, que são suas vizinhas. Em poucos minutos a sala já estava repleta e quando a reprodução começou instaurou-se um silêncio nunca ocorrido durante a filmagem. As crianças concentraram-se para escutar a avó. Fiquei impressionada: estava claro que aquelas narrativas despertavam agora o interesse de todos. Este, porém, era motivado pelo meio através do qual elas eram transmitidas, a televisão.

O evento ainda se complexificou mais quando a filha de Dona Nair pediu que eu fotografasse a imagem que aparecia na televisão. A princípio não compreendi, mas não fingi inteligência e perguntei o porquê do pedido. Ela então me explicou que através da foto poderia mostrar para os outros vizinhos e parentes "a mãe na televisão". Coube-me concluir que a capacidade narrativa de Dona Nair havia sido legitimada pela reprodução do vídeo e confirmada pelo registro fotográfico, especialmente porque este último representava a disponibilização de um objeto concreto (a foto) que poderia ser utilizado como uma espécie de prova material do ocorrido. 
A “mãe na televisão" me despertou para a questão de que a imagem reproduzida tem se constituído, mesmo naquelas sociedades que têm com ela um contato menos intenso, como um meio de legitimação do saber ${ }^{8}$. Problematizar esta questão e pensá-la para que este canal de legitimação possa servir para que pequenos grupos se conheçam e transmitam conhecimentos entre si, é também um dos objetivos de meu trabalho.

Outro diferencial da pesquisa realizada com suporte audiovisual é o fato de que, a partir das imagens e sons apresentados pelo(a) antropólogo(a), ela pode ser melhor compreendida pelos próprios sujeitos nela envolvidos. Neste sentido, a estratégia de levar fotos dos principais contadores e dos diversos lugares onde estive e de mostrálas a cada novo encontro, representou, em muitas ocasiões, um 'atalho' no estabelecimento de uma relação de confiança e cumplicidade com esses sujeitos.

Numa fazenda de Massoler/UY, onde eu só poderia permanecer três dias, o recurso às fotografias me valeu uma aproximação com o capataz e com os peões que certamente de outra maneira demandaria uma permanência muito mais longa. Cheguei acompanhada da proprietária da estância, que iria embora no dia seguinte e como de praxe ela me apresentou em primeiro lugar ao capataz, Seu João, e logo depois à cozinheira e ao seu esposo. Quanto aos peões, realizavam seu trabalho no campo e como não é costume haver um contato mais direto entre eles e os convidados dos patrões, não cheguei a conhecê-los neste momento.

Na primeira oportunidade que tive, depois do almoço, mostrei algumas fotos da pesquisa aos proprietários, ao veterinário e ao capataz. Este, aos poucos, foi se interessando pelo material e como reação trouxe fotos suas, de rodeios e marcações de gado, para me mostrar. À noite vim a saber pela cozinheira que Seu João ficara, a princípio, bastante desconfiado com a minha presença ali, especialmente por não compreender bem quais eram meus propósitos. Segundo ela, as fotos o 'amaciaram'. Seu João acabou sendo um ótimo interlocutor e nos poucos dias em que estive na estância acompanhou-me entusiasmado, mostrando-me o local, apresentando-me aos peões e, claro, contando-me histórias. Quanto aos peões, restava-me superar a barreira de estabelecer um contato produtivo em pouco tempo, então já na primeira noite 'armei-me' de fotos e, na companhia de Seu João, fui encontrá-los no galpão, onde descansavam e tomavam mate. Os onze homens me receberam com o silêncio e o respeito habitual. Após alguns mates, tomei a iniciativa: abri minha enorme pasta de fotos e fui Ihes mostrando uma a uma, contando-Ihes um pouco de cada lugar e de cada pessoa retratada (foto 2 - peões Brasil). Não demorou muito para que um deles reconhecesse um espaço de rodeios que eu fotografara em Rivera/UY. Outro pensou reconhecer um amigo brasileiro, peão também, e começou a contar sobre as diferentes estâncias onde trabalhara, no Brasil e no Uruguai. Em pouco tempo todos comentavam, comigo e entre si, temas suscitados pelas imagens. A dificuldade, a partir daí, foi conseguir dar conta, sozinha, de apreender todas as informações, comentários, chistes e pequenas histórias advindas deste encontro. 


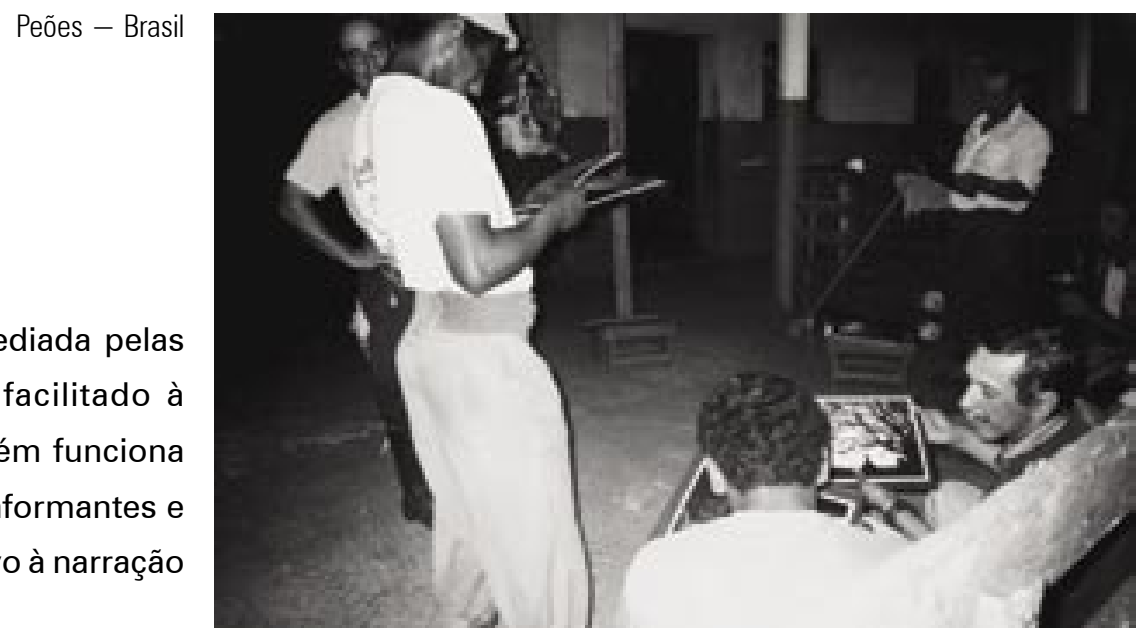

Como se percebe, a aproximação mediada pelas fotos gera não apenas um acesso facilitado à compreensão da pesquisa mas também funciona como um estímulo ao diálogo entre informantes e antropólogo(a), bem como um incentivo à narração de histórias. Como afirma Bittencourt:

"A contribuição que a imagem traz ao registro etnográfico não se resume, portanto, na valorização da técnica que gera imagens similares ao mundo sensível, mas reside no fato de que essas imagens são produtos de uma experiência humana. Na realidade, a imagem e os meios visuais, quando utilizados como instrumentos etnográficos, ampliam as condições para o estabelecimento de um diálogo fecundo com outros universos culturais" (1998:200).

Não foram poucas as ocasiões em que as fotos suscitaram cuentos, revelaram histórias de família e trouxeram à tona relações obscurecidas pelo tempo ou pela falta de referenciais imagéticos. Foi o que ocorreu na conversa que tive com Dona Gegê e sua amiga Araceli. Eu havia recebido uma indicação de procurar Dona Gegê pois ela, como única enfermeira de Moirones/UY, conhecia muitas histórias. No entanto, eu já estava uma tarde inteira na sua companhia e ela permanecia calada, apenas acompanhando com sonoras gargalhadas as narrativas que a amiga contava. No final do dia, antes de me despedir, resolvi mostrar a elas um álbum de fotos da pesquisa, com imagens que mostravam sobretudo a comunidade vizinha, Cerro Pelado, onde eu havia passado as últimas semanas. Como de costume, eu ia descrevendo eventos, identificando pessoas, locais etc. Ao mostrar-Ihes uma determinada foto, deu-se a 'revelação'. Transcrevo o episódio na íntegra, no sentido de preservar a riqueza e o inesperado do diálogo:

Eu [mostrando a foto] - Essa é a mãe do Coquito, a Dona Julieta.

Dona Gegê - Quem?

$E u$ - Essa é a Dona Julieta.

$D G$ - Ahhhhh, Dona Julieeeeeta!!!! [risos] Esta? 
Eu - Ahã, essa aqui ó [mostro outra foto], a mesma.

$D G$ - Eeeesta era a bicha que me traicionava! [risos]

$E u$ - Ah, éééé?

Dona Araceli - Vai ter zelo [ciúmes] agora, Gegê?

$D G$ - Mas eu nunca pude conhecer a tal de Julieta, tu sabe?

$D A$ - Só em foto agora tu conheceu.

$D G$ - Agora vim a conhecer em foto.

$E u$ - O que, Dona Gegê?

$D G$ - Ééééé...

$D A$ - Esta que vivia com o esposo dela.

Eu - É mesmo?

$D G$ - Que nós tinha uma chácara em Cerro Pelado, um pedacinho de campo, não? E ele ficava dois, três dias lá, despôs tava uma semana aqui, ou tava uma semana lá e quatro ou cinco dias nas casas. E nesse meio... Como eu trabalhava aqui, não podia ir pra lá morar com ele, não é? Então ele que ia e vinha e eu... às vezes, fim-de-semana, ia. Às vezes ia uns dias e ficava lá com ele, quando havia faena [trabalho que na região identifica a carneada conjunta de uma vaca e de um porco], assim, essas coisas. Bueno, aí despôs ele tava fazendo uma casinha e um dia eu fui daqui. E o Bicuco, parente desta [refere-se à amiga], tava lá fazendo a casa e me contou... empezou a me contar que...

$D A$ - Bicuco fofoqueiro!

$D G$ - Que tinha aparecido um mundo de coisa lá na livreta [livro de contas do armazém] e me contou que apareceu erva e não sei o que más... e me dizia: "Mas se a Gegê chega a saber!" E me contou... [ela ri] $D A$ - Que fofoqueiro...

$D G$ - E aí despôs o Nardo, que era pequeno, meu filho, uma volta ele me disse que ia passear na Julieta com o papai e que o papai dava coca-cola pra ele não contar que ia lá na Julieta. [ela ri]

$D A$ - Pero a véia é muito más veia que tu!

$D G$ - Más claro que é muito más velha!

Eu - Claro, claro...

$D G$ - Mas o meu marido também...

$D A$ - Que sem-vergonha!

$E u$ - Mas isso faz anos já, do seu marido?

$D G$ - Sim, só que eu sou viúda já faz seis anos.

Eu - Que danado, né... [risos] 
Assim Dona Gegê via, através das minhas fotos, pela primeira vez, o rosto da amante de seu falecido marido. Felizmente a situação se encaminhou de maneira muito leve e divertida. E eu pude conhecer um pouco melhor as relações de vizinhança na região...

Em outros casos, o não-reconhecimento também aporta valiosas informações. Como já coloquei anteriormente, mantenho sempre a prática de retornar aos locais e presentear os narradores com suas melhores fotos (e outras de seu agrado, quando são solicitadas). Numa destas ocasiões, ao entregar a Don Suarez as fotos tiradas durante uma faena (atividade onde se carneia uma vaca e um porco) realizada em sua casa, ele não se reconheceu. Tive que indicar-lhe com precisão a própria imagem, apontando referenciais que comprovassem o que eu dizia. Há várias interpretações possíveis para este não-reconhecimento, mas entre elas fico com aquela dada pelo próprio Don Suarez, que comentou que ali parecia "muito bonito". Possivelmente o que ele via como "bonito" dissesse respeito mais ao formato e à composição das fotografias como um todo do que à sua própria figura: as imagens eram nítidas, com cores vivas e reproduziam a seqüência de ações executadas pelos homens ao carnearem uma vaca, congelando cenas e com isso salientando aspectos desta atividade que dificilmente são percebidos durante o evento. $\mathrm{O}$ fato de as cópias serem feitas em papel fosco, com uma margem branca, talvez também tenha contribuído para a reação de estranhamento de Don Suarez àquelas imagens. Talvez este nãoreconhecimento também aponte para uma característica desta cultura, especialmente relativa aos mais idosos: o seu olhar está dirigido para fora, para o outro ${ }^{9}$. A auto-imagem, o reflexo no espelho, a fotografia ou o retrato de si praticamente inexistem neste universo ${ }^{10}$.

Incorporando a noção de que o olhar também é culturalmente construído, é possível aferir que, na zona pesquisada, a cultura instrumentaliza o olhar mais para o outro do que para si. Para tanto, é importante lembrar que esta é uma região de fronteira e que nestas regiões as identidades são criadas a partir de diferenciais que permitem estabelecer quem é o outro e quais são as características que definem a sua noção de alteridade. Como verifiquei ao longo da pesquisa, esta 'área cultural' que congrega as três fronteiras possui muitas afinidades, muitas semelhanças, muitas identidades. Pois bem, ainda que para os seus habitantes esta convergência de valores, de tradições e de histórias se confirme, há demarcações visíveis, porém sutis, que impõem limites entre o 'nós' uruguaio, o 'nós' argentino e o 'nós' brasileiro. No caso de minha pesquisa, os comentários e observações feitos constantemente às imagens mostradas aos contadores de um país e de outro, em especial àquelas relativas a eventos sociais, como rodeios, criollas (festas campeiras), carreiras (corridas de cavalo) etc., foram fundamentais para que eu acedesse à compreensão de alguns desses demarcadores identitários.

Quando adentrei o lado uruguaio da fronteira, por exemplo, me surpreendiam as afirmações categóricas dos narradores a respeito de algumas fotos: "Ah! Mas estes são brasileiros!", referindo-se a uma série de imagens 
onde peões - brasileiros - trabalhavam na difícil tarefa de castração de cavalos chucros. Nas várias ocasiões em que ouvi esse comentário, interrogava-Ihes sobre como poderiam saber com tanta precisão a nacionalidade dos peões, considerando que se tratava de uma fazenda 'na fronteira', o que conferia a todos, ao menos para mim, características absolutamente semelhantes. As respostas giravam em torno de um eixo comum, baseado, por um lado, nas atitudes corporais, no comportamento físico dos peões e, por outro lado, nas características de suas vestimentas, como cores e formatos.

Recorramos às fotos. Em uma delas (foto 3 - castração Brasil), tirada em um dia de castração de cavalos numa estância de Uruguaiana/BR, os 'índices' de brasilidade apontados pelos peões uruguaios foram encontrados nas botas: somente brasileiros usam botas de couro claro; nas bombachas (calças largas, presas por botões logo acima dos tornozelos) - bem mais largas que as uruguaias - e nos chapéus, diferentes dos uruguaios pelo formato e pelo tamanho das abas. Vários uruguaios também chamaram minha atenção para a postura dos peões, segundo eles "tipicamente brasileña" (o fato de que um deles acende um cigarro enquanto prende a cabeça do cavalo com o pé e de que o outro está parado displiscentemente segurando a corda). Outra característica mencionada foram as cores das suas camisas (uma lilás, outra vermelha) que, de acordo com eles, são tonalidades dificilmente encontradas nas vestimentas de peões uruguaios. A observação de eventos em seu país, no entanto, acabou demonstrando o contrário: gauchos uruguaios também se vestem com cores chamativas. A análise deste fato permite retomar a questão abordada acima, de que o olhar da população está voltado para o exterior, logo, as percepções sobre o outro são mais acuradas do que a percepção de si mesmo.

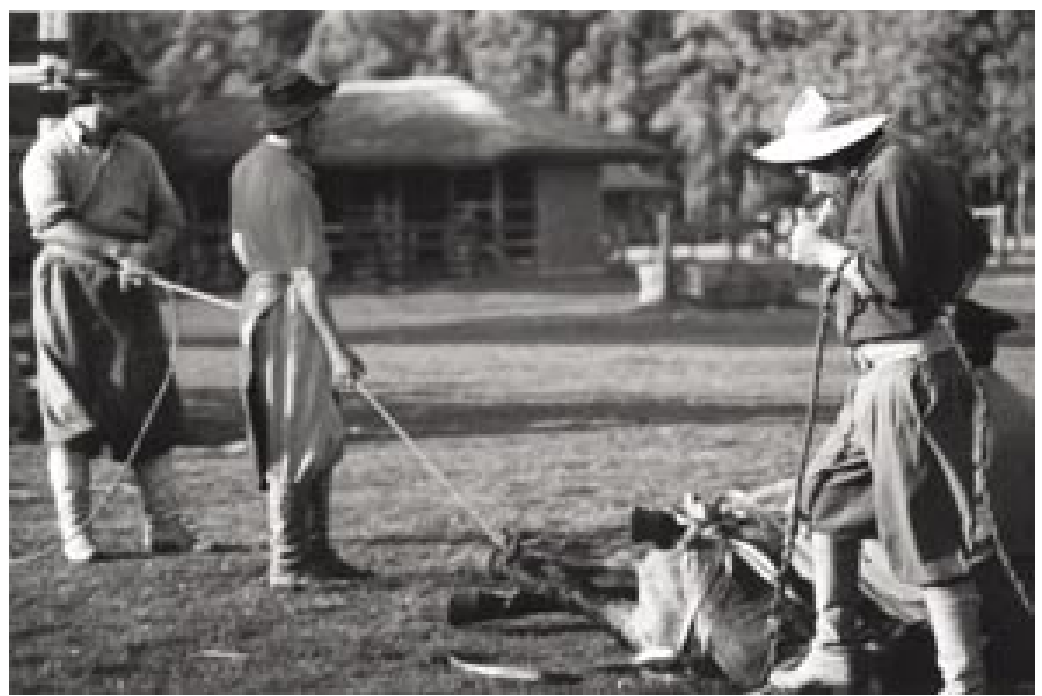

Castração - Brasil

No decorrer da pesquisa de campo, como fui acrescentando ao meu 'mostruário' fotos de eventos e de contadores dos três países, as observações feitas a respeito das especificidades de cada país foram se complexificando e aos poucos eu já podia identificá-las antes mesmo de seus comentários, ainda que nunca os dispensasse. Resultava impressionante a 
possibilidade de distinção - dentro da cultura englobante, 'da fronteira' ${ }^{11}$, por assim dizer (composta de trabalhadores rurais, moradores da região, gaúchos e gauchos...) - das nuances que identificavam as culturas locais, cujos referenciais, necessários na busca de distinção deste 'outro' tão próximo, voltavam-se para suas respectivas culturas nacionais. Assim, a alcunha gaúcho/gaucho, quando utilizada nestas observações, vinha sempre adjetivada pela identificação do país de origem: "Pero ese es un gaucho argentino, mirá la polaina"; "Os gaúchos uruguaios é que usam chapéu pontudo"; "Las chinas uruguayas no son como las prendas brasileñas" etc.

As interpretações das imagens também apontaram para alguns aspectos privilegiados pela cultura da fronteira em questão. Uma das fotos (foto 4 - criollas Uruguai), mostrada para habitantes de qualquer um dos três países, sempre chamou a atenção destes para a presença de um personagem que a mim parecia secundário: o policia. Neste sentido, a observação de Guran complementa minha argumentação:

(...) "a função da fotografia (como um instrumento da observação participante) é a de destacar um aspecto de uma cena a partir do qual seja possível se desenvolver uma reflexão objetiva sobre como os indivíduos ou os grupos sociais representam, organizam e classificam suas experiências e mantêm relações entre si. (...) As entrevistas feitas com fotografias permitem, por exemplo, que aspectos apenas percebidos ou intuídos pelo pesquisador sejam vistos - e se transformem em dados - a partir dos comentários do informante sobre a imagem (1998:160).

Criollas - Uruguai

Esta imagem, feita num dia de Criollas (festa tradicional, com provas campeiras, apresentação de danças tradicionais, churrasco e baile), em Cerro Pelado/UY, era para mim representativa de determinados comportamentos sociais locais, como a configuração espacial de acordo com papéis de gênero (homens de um lado da cerca, mulheres de

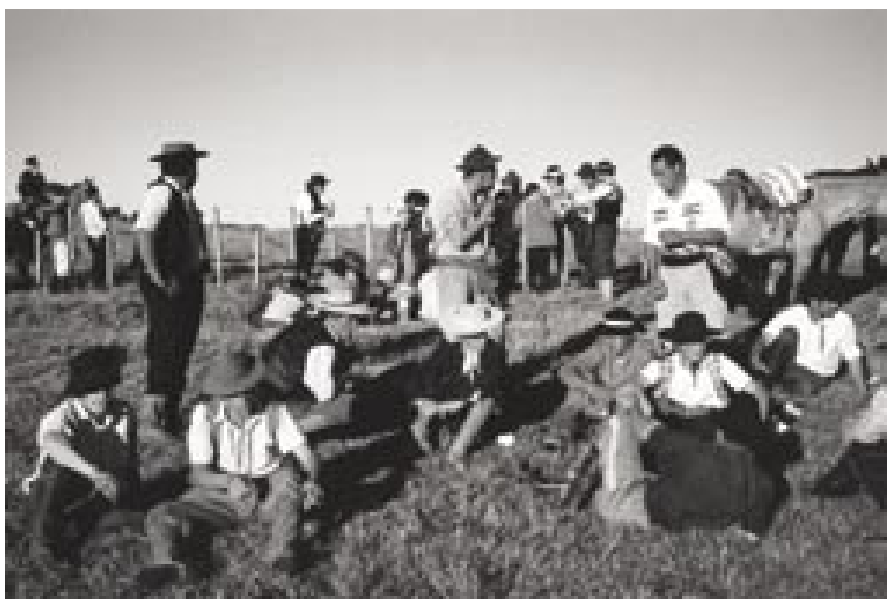
outro), as diferentes posturas de descanso do grupo masculino etc. Já os narradores colocavam grande ênfase na presença do policia, e seus comentários oscilavam entre uma certa desconfiança e o deboche. Estes comentários me fizeram atentar para o fato de que autoridades institucionais dificilmente são bem-vindas em eventos deste caráter, onde freqüentemente ocorrem jogos com apostas em dinheiro, que são proibidas, e eventualmente brigas 
entre borrachos. Nesta sociedade, onde as histórias de conflito e violência são tão recorrentes, não era de estranhar, portanto, que a figura do policia, tanto como representante da lei, como também agente da violência, fosse tão referenciada.

Em outros casos, a atenção dos habitantes recaía sobre a raça e o tipo de pelagem dos cavalos que apareciam nas fotos, questão que algumas vezes despertava acirradas discussões e me alertava para a importância do animal para esta cultura. Esta questão estimulou minha percepção para a presença constante de quadros, calendários e acessórios relativos a estes animais, como ferraduras e laços, utilizados como objetos de decoração em praticamente todas as casas que conheci na região.

Outras fotos despertavam críticas: como pode um gaúcho pilchado usando championes (tênis)? Este comentário demonstra uma percepção - cultural - do que pode ou deve ser fotografado/filmado, isto é, o que os membros do grupo querem que seja transmitido - revelado em imagens - a seu respeito ${ }^{12}$. Assim, como já foi mencionado, o diálogo a partir de imagens também pode fazer emergir, na negação ou na recusa do que elas revelam, regras, valores, códigos - nem sempre explícitos - da cultura em questão.

Em relação à exibição dos vídeos, mais rara devido às dificuldades de adaptação do próprio equipamento aos monitores disponíveis, houve reações também remarcáveis. Se por um lado as imagens legitimavam o saber de seu protagonista, por outro lado um dos principais fatores que sustentam essa legitimação é o referencial de registro das imagens, a 'realidade'. Ou seja, de acordo com o que ouvi nos comentários, a imagem não apenas mostra como também reforça o 'real': este fato aconteceu, por isso merece ser filmado, transmitido através desse meio.

A relação do audiovisual com a 'realidade' - no sentido adotado pelos narradores - ficou patente em diversas situações, como quando exibi o vídeo produzido durante a minha pesquisa de mestrado para Seu Romão e sua família. Neste vídeo, que tem Seu Romão como protagonista, ele conta um 'causo' sobre uma tocaia feita a um lobisomem. Ao se ver contando a história, ele comentou: “Isso foi mesmo fato, dona. Aconteceu bem assim como eu conto aí."

Em outras ocasiões, quando as imagens brutas eram exibidas após uma festa ou um evento narrativo, os comentários giravam em torno do mesmo referencial: a realidade que ali era mostrada. Numa noite mostrei a duas famílias conhecidas as gravações que havia feito das Criollas, das quais elas participaram. Suas observações enquanto assistiam iam desde a habilidade de um ginete ao tamanho da espora usada por um peão, ou ainda a um detalhe numa bombacha ou chapéu (de brasileiro!) etc. Mas todos vibraram mesmo foi com o momento da gineteada: gritavam, torciam, exatamente como faziam no momento do evento, fazendo críticas e observações técnicas. 
Percebi entretanto que, ao contrário do que eles esperavam, eu não havia privilegiado seqüências inteiras dos ginetes - momento clímax do evento - e muitas vezes dirigia meu olhar (e o foco da câmera) para acontecimentos secundários. Estes acontecimentos, que para os sujeitos da pesquisa não despertavam interesse, para mim revelavam relações sociais, atitudes e comportamentos significativos. Após essas exibições, muitas vezes refleti sobre este procedimento que, apesar de aportar informações importantes para a pesquisa, também colocava meu olhar em questão. Assim como os sujeitos me punham a par, com suas observações, dos interstícios de sua cultura, eu ali expunha, sem atenuantes, meus interesses e minha maneira, na visão deles talvez injusta, de recortar a sua realidade.

Ao mostrar as imagens sem edição, tive de assumir os riscos e enfrentar situações por vezes constrangedoras, como quando a mãe de uma garotinha aborreceu-se nitidamente comigo por haver filmado pouco a apresentação de danças folclóricas do grupo de sua filha. Ou ainda quando, numa exibição, começaram a aparecer detalhes da postura e do gestual de um peão, e sua esposa, que estava assistindo, olhou-me desconfiada pelo fato de o marido aparecer tanto. Nesses momentos contornei o desconforto da situação explicando com minúcia como e para que o material audiovisual seria utilizado, explicitando que estes 'recortes' eram necessários para cumprir com os objetivos específicos da pesquisa - como a questão das expressões corporais tão características dos gaúchos/gauchos - e assumindo a autoria e responsabilidade sobre o que havia sido registrado.

Como procurei desenvolver ao longo deste artigo, a compreensão de minha pesquisa, por parte dos sujeitos nela envolvidos, passa pelo equipamento que manipulo e pelo material fotográfico e videográfico que apresento - acrescido e transformado a cada nova temporada em campo. Por outro lado, minha compreensão da sociedade pesquisada também passa pela relação que eu e estes sujeitos desenvolvemos neste contato com/através das imagens. Nas suas interpretações acerca das próprias imagens e das imagens dos 'outros' aprendo um pouco mais sobre sua cultura e sobre seu modo de ver a cultura. E através de nossos diálogos, continuamos perseguindo possibilidades de comunicação entre nossas culturas.

Luciana Hartmann é doutora em Antropologia Social pela Universidade Federal de Santa Catarina, tendo realizado doutoradosanduíche na École des Hautes Études en Sciences Sociales (Paris), e atua como professora substituta no Departamento de Antropologia Cultural da Universidade Federal do Rio de Janeiro. 


\section{NOTAS}

1 Estou de acordo com a crítica de Piault (1999:15) ao uso do termo "antropologia visual", pois esta ocultaria uma parte do domínio que a constitui, contemplado, ao contrário, na designação "antropologia audiovisual".

2 A experiência proporcionada pela "observação participante", exatamente porque é de difícil apreensão, tem servido como uma eficaz garantia, segundo Clifford (1998: 38), à autoridade etnográfica.

3 Na verdade, as imagens não estão em movimento, mas dispostas seqüencialmente numa determinada velocidade (inicialmente 16 e agora 24 fotogramas por segundo) que dá a impressão de movimento.

4 Piault vai demonstrar que etnografias como a de Boas, e posteriormente muitas outras, inseriam-se nesta perspectiva de realização de uma coleção concreta de formas de sociabilidade, onde a imagem funcionava como um instrumento desta "coleção da realidade do mundo" e de uma "objetivação" do olhar.

5 Desde Haddon e Rivers, que levaram uma filmadora em sua expedição ao Estreito de Torres, em 1895, passando por Flaherty - que realizou, em 1922, o clássico Nanook of the North, sobre a vida dos Inuit do Canadá - e pelo casal Mead e Bateson - que no fim dos anos 30 realizou um majestoso empreendimento de registro fílmico e fotográfico em Bali e na Nova Guiné (do qual constaram 25 mil fotos e seis mil metros de película) -, a história da antropologia vem sendo construída com imagens. Para maiores considerações sobre o papel destes registros nas obras de cada um destes autores/realizadores, e para um histórico mais detalhado da relação da antropologia com a imagem, ver Novaes (1998), Piault (2000) e Samain (1995).

6 Não tenho a ilusão, no entanto, de que o audiovisual dá conta da totalidade.

7 Para maiores informações sobre o tema, ver Goody (1999), Lévy (1993), Samain (1998), Eckert \& Carvalho da Rocha (2000) e Carvalho da Rocha (2003).

8 Em diversas outras ocasiões este aspecto foi reforçado. Ao reencontrar Seu Ordálio, por exemplo, de Uruguaiana/BR, ele logo quis me mostrar uma novidade: na área coberta, construída nos fundos da sua casa, junto a uma churrasqueira, seus filhos colocaram pôsteres seus como cabanheiro premiado e uma foto em que aparece sendo abraçado por Getúlio Vargas. Ao mostrar-lhe minha dissertação ele, ao ver que aparece numa foto, comentou com o neto: "Mas que importância, hein!"

9 Inspiro-me aqui em trabalho de Vernant (1987:38) onde este, discorrendo sobre a noção de indivíduo entre os gregos arcaicos e clássicos, coloca: "O sujeito não constitui um mundo interior fechado, no qual deve penetrar para se encontrar, ou antes, para se descobrir. O sujeito é extrovertido. Do mesmo modo que o olho não se vê a si próprio, o indivíduo para se apreender olha para o outro, para o exterior."

10 Nos ranchos mais rústicos, feitos de barro e cobertos com sapé, como o de Don Suarez (ainda bastante comuns na zona de fronteira do Uruguai e da Argentina e menos recorrentes no Brasil), e especialmente naqueles onde residem apenas homens, os espelhos são quase inexistentes e as únicas fotografias são aquelas utilizadas em documentos - em geral com representações suas ainda da juventude.

11 Em minha tese de doutorado (Hartmann 2004) argumento que há uma cultura comum que liga os habitantes dos três países fronteiriços, uma cultura 'da fronteira' que se desenvolveu paralelamente às suas respectivas culturas nacionais.

12 É o que Piault (2000:191) identifica como um controle social local sobre a produção de imagens - um direito dos grupos estudados cada vez mais exigido na atualidade. 


\section{REFERÊNCIAS BIBLIOGRÁFICAS}

ACHUTTI, Luiz Eduardo (org.). 1998. Ensaios (sobre o) Fotográfico. Porto Alegre: Unidade Editorial.

BAUMANN, Richard. 1977. Verbal Art as Performance. Rowley, Mass, Newbury House Publishers.

BIANCO, Bela Feldman. 1998. "Caixões infantis expostos: o problema dos sentimentos na leitura de uma fotografia". In B. F. Bianco \& M. Leite (orgs.). Desafios da Imagem: fotografia, iconografia e vídeo nas ciências sociais. Campinas/SP: Papirus.

BITTENCOURT, Luciana A. 1998. "Algumas considerações sobre o uso da imagem fotográfica na pesquisa antropológica". In B. F. Bianco \& M. Leite (orgs.). Desafios da Imagem: fotografia, iconografia e vídeo nas ciências sociais. Campinas/SP: Papirus.

CARVALHO DA ROCHA, Ana Luísa. 1995. "Antropologia das formas sensíveis: entre o visível e o invisível, a floração de símbolos". Horizontes Antropológicos - Antropologia Visual 2: 85-91.

1999. "Antropologia visual: um convite à exploração de encruzilhadas conceituais". In C. Eckert \& P. MonteMor (orgs.). Imagem em Foco - Novas Perspectivas em Antropologia. Porto Alegre: PPGAS/Editora da UFRGS. 2003. "Tecnologias audiovisuais na construção de narrativas etnográficas, um percurso de investigação". Campos 4: 113-34.

CLIFFORD, James. 1998. A Experiência Etnográfica - antropologia e literatura no século XX. Org. José R. S. Gonçalves. Rio de Janeiro, Editora UFRJ.

DARBON, Sébastien. 1998. “O etnólogo e suas imagens”. In E. Samain (org.) O Fotográfico. São Paulo: HUCITEC/CNPq. DUBOIS, P. 1994. O Ato Fotográfico e Outros Ensaios. Campinas/SP: Papirus.

FONSECA, Claudia. 1995. "A noética do vídeo etnográfico". Horizontes Antropológicos - Antropologia Visual 2: 143-56.

FRANCE, Claudine de (org.). 2000. Do Filme Etnográfico à Antropologia Fílmica. Campinas/SP: Editora da UNICAMP.

FRANCE, Claudine de. 1998. Cinema e Antropologia. Campina/SP, Editora da UNICAMP.

GALLOIS, D.; CARELLI, V. 1995. “Vídeo e diálogo cultural - experiências do Projeto Vídeo nas Aldeias”. Horizontes Antropológicos - Antropologia Visual 2: 49-57.

GEERTZ, Clifford. 1989a. El Antropologo como Autor. Barcelona, Paidos.

1989b. A Interpretação das Culturas. Rio de Janeiro, Guanabara Koogan.

GINSBURG, Faye. 1999. "Não necessariamente o filme etnográfico: traçando um futuro para a antropologia visual”. In C. Eckert \& P. Monte-Mor (orgs.). Imagem em Foco - Novas Perspectivas em Antropologia. Porto Alegre: PPGAS/Editora da UFRGS.

GODOLPHIM, Nuno. 1995. “A fotografia como recurso narrativo: problemas sobre a apropriação da imagem enquanto mensagem antropológica". Horizontes Antropológicos - Antropologia Visual. 2: 125-42.

GOODY, Jack. 1999. Representaciones y Contradiciones. Barcelona/Buenos Aires/México: Paidós.

GUÉRONNET, Jane. "Ritualismo e cooperação em u. ma técnica do corpo”. In C. De France (org.) Do Filme Etnográfico à Antropologia Fílmica. Campinas/SP: Editora da UNICAMP. 
GURAN, Milton. 1998. "A "fotografia eficiente" e as ciências sociais". In L. E. Achutti (org.) Ensaios (sobre o) Fotográfico. Porto Alegre: Unidade Editorial.

HARTMANN, Luciana. 2004. "Aqui nessa fronteira onde tu vê beira de linha tu vai ver cuento" - Tradições orais na fronteira entre Argentina, Brasil e Uruguai. Tese de doutorado. Florianópolis: UFSC.

KOSSOY, Boris. 1998. "Fotografia e memória: reconstituição por meio da fotografia”. In E. Samain (org.) O Fotográfico. São Paulo: HUCITEC/CNPq.

LEITE, Míriam L. M. 1998. "Retratos de Família: imagem paradigmática no passado e no presente". In E. Samain (org.) $O$ Fotográfico. São Paulo: HUCITEC/CNPq.

LÉVY, Pierre. 1993. As Tecnologias da Inteligência - o futuro do pensamento na Era da Informática. Rio de Janeiro: Ed. 34.

LIMA, Francisco Assis de Sousa. 1985. Conto Popular e Comunidade Narrativa. Rio de Janeiro: FUNARTE/ Instituto Nacional do Folclore.

LOURDOU, Philippe. 2000. "O comentário nos filmes etnográficos de Marcel Griaule". In C. De France (org.) Do Filme Etnográfico à Antropologia Fílmica. Campinas/SP: Editora da UNICAMP.

MAGNI, Claudia T. 1995. "O uso da fotografia na pesquisa sobre habitantes da rua". Horizontes Antropológicos - Antropologia Visual 2: 111-16.

MARESCA, Sylvain. 1998. “Olhares Cruzados. Ensaio comparativo entre as abordagens fotográfica e etnográfica”. In E. Samain (org.) O Fotográfico. São Paulo: HUCITEC/CNPq.

NOVAES, Sylvia C. 1998. “O uso da imagem na antropologia”. In E. Samain (org.) O Fotográfico. São Paulo: HUCITEC/ CNPq.

OLIVEIRA Jr., Antônio R. de. 1998. “O visível e o invisível: um fotógrafo e o Rio de Janeiro no início do século XX”. In E. Samain (org.) O Fotográfico. São Paulo: HUCITEC/CNPq.

PEIXOTO, Clarice. 1995. "O jogo de espelhos e das identidades: as observações comparada e compartilhada". Horizontes Antropológicos - Antropologia Visual 2: 69-84.

PIAULT, Marc Henri. 1999. “Espaço de uma antropologia audiovisual”. In C. Eckert \& P. Monte-Mor (orgs.). Imagem em Foco - Novas Perspectivas em Antropologia. Porto Alegre: PPGAS/Editora da UFRGS.

2000. Anthropologie et Cinema. Paris: Nathan.

PÓLVORA, Jacqueline Britto. 1995. "Experiência de antropologia visual em uma casa de batuque de Porto Alegre". Horizontes Antropológicos - Antropologia Visual 2: 101-109.

RIAL, Carmen Sílvia. 1999. “Japonês está para a TV assim como mulato está para cerveja: imagens da publicidade no Brasil". In C. Eckert \& P. Monte-Mor (orgs.). Imagem em Foco - Novas Perspectivas em Antropologia. Porto Alegre: PPGAS/Editora da UFRGS.

ROSENFELD, Jean-Marc. 2000. "Filmar: uma reconversão do olhar". In C. De France (org.) Do Filme Etnográfico à Antropologia Fílmica. Campinas/SP: Editora da UNICAMP.

SAMAIN, Etienne. 1995. " "Ver" e "dizer" na tradição etnográfica: Bronislaw Malinowski e a Fotografia". Horizontes Antropológicos - Antropologia Visual 2: 19-48. 
1998 (org.). O Fotográfico. São Paulo: HUCITEC/CNPq.

SEL, Susana. 1995. "Reflexiones en antropología visual". Horizontes Antropológicos - Antropologia Visual 2: 117-24.

SOARES, Luiz Eduardo. 1994. O Rigor da Indisciplina. Rio de Janeiro: Relume-Dumará.

VALADÃO, Virgínia M. 1999. “O processo de trabalho do vídeo Yãkwá - o banquete dos espíritos”. In C. Eckert \& P. MonteMor (orgs.). Imagem em Foco - Novas Perspectivas em Antropologia. Porto Alegre: PPGAS/Editora da UFRGS.

VERNANT, Jean-Pierre. 1987. Indivíduo e Poder. Lisboa: Edições 70. 
'Revelando' histórias: os usos do audiovisual na pesquisa com narradores da fronteira entre Argentina, Brasil e Uruguai

\section{RESUMO}

O trabalho com audiovisual na pesquisa antropológica envolve não apenas o desenvolvimento de um conhecimento técnico específico mas, sobretudo, a reflexão sobre o papel que estes instrumentos e produtos de registro e representação da realidade podem ter, tanto na realização da pesquisa de campo quanto no momento de análise e interpretação da cultura estudada. Neste artigo abordo as diferentes implicações que o audiovisual pode ter na atividade antropológica, tendo como parâmetro minha experiência de pesquisa entre contadores de causos/cuentos da fronteira entre Argentina, Brasil e Uruguai. Esta abordagem leva em conta questões ligadas à teoria, à prática, à técnica e à ética na transmissão e troca de conhecimentos através da linguagem audiovisual.

PALAVRAS-CHAVE: imagem, antropologia visual, contadores de histórias, fronteira, oralidade.

'Developing' histories: audiovisual uses in research among story-tellers of the Argentina/Brazil/Uruguay border

\section{ABSTRACT}

The use of audio-visual resources in social sciences is related to the development of specific technical knowledge but also, a more importantly, presupposes a reflection on the role these resources and means of representation have on fieldwork as well as on analysis and interpretation of any given culture. In this paper I emphasize different implications of audio-visual resources in anthropological activity having as parameter my research experience among storytellers of the borderline of Argentina, Brazil, and Uruguay. This approach considers theory, practice, technique and ethics in transmission and exchange of knowledge by audio-visual language.

KEYWORDS: image, visual anthropology, storytellers, border, orality. 